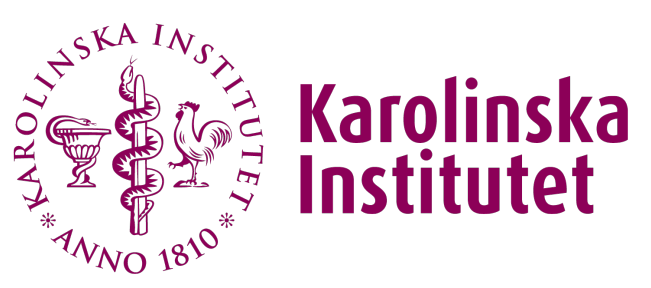

Karolinska Institutet

http://openarchive.ki.se

This is a Peer Reviewed Accepted version of the following article, accepted for publication in The Spine Journal.

\title{
An observational study on the outcome after surgery for lumbar disc herniation in adolescents compared to adults based on the Swedish Spine Register
}

Lagerbäck, Tobias; Elkan, Peter; Möller, Hans; Grauers, Anna; Diarbakerli, Elias; Gerdhem, Paul

Spine J. 2015 Jun 1;15(6):1241-7.

http://doi.org/10.1016/j.spinee.2015.02.024

http://hdl.handle.net/10616/44764

If not otherwise stated by the Publisher's Terms and conditions, the manuscript is deposited under the terms of the Creative Commons Attribution-NonCommercial-NoDerivatives License (http://creativecommons.org/licenses/by-nc-nd/4.0/), which permits non-commercial re-use, distribution, and reproduction in any medium, provided the original work is properly cited, and is not altered, transformed, or built upon in any way. 


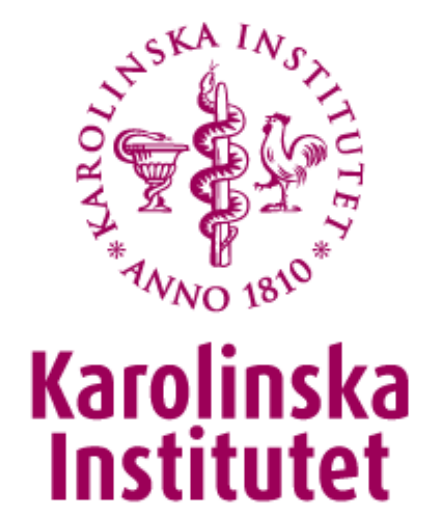

This is an author produced version of a paper published in Spine Journal. This paper has been peer-reviewed but does not include the final publisher proof-corrections or journal pagination.

Citation for the published paper:

Spine J. 2015 Jun 1;15(6):1241-7. doi:

10.1016/j.spinee.2015.02.024. Epub 2015 Feb 17.

DOI: $10.1016 /$ j.spinee.2015.02.024

Access to the published version may require subscription.

Published with permission from: Elsevier Inc. 


\section{An observational study on the outcome after surgery for lumbar disc herniation in adolescents compared to adults based on the Swedish Spine Register.}

Lagerbäck T $T^{\mathrm{a}}$, Elkan $\mathrm{P}^{\mathrm{a}, \mathrm{b}}$, Möller $\mathrm{H}^{\mathrm{a}}$, Grauers, $\mathrm{A}^{\mathrm{a}, \mathrm{c}}$, Diarbakerli, E $\mathrm{E}^{\mathrm{a}}$, Gerdhem $\mathrm{P}^{\mathrm{a}}$ ${ }^{\mathrm{a}}$ Department of Clinical Sciences, Intervention and Technology (CLINTEC), Karolinska Institutet, Department of Orthopaedics, Karolinska University Hospital, Stockholm, Sweden Tobias Lagerbäck

${ }^{\mathrm{b}}$ Department of Clinical Sciences, Södersjukhuset, Karolinska Institutet, Department of Orthopaedics, Södersjukhuset, Stockholm, Sweden

${ }^{c}$ Department of Orthopaedics, Sundsvall and Härnösand County Hospital, Sundsvall, Sweden

\section{Corresponding author}

Paul Gerdhem, Department of Clinical Sciences, Intervention and Technology (CLINTEC), Karolinska Institutet, and Department of Orthopaedics, K54, Karolinska University Hospital, Huddinge, SE 141 86, Stockholm, Sweden

E-mail: paul.gerdhem@karolinska.se

Telephone: +46-8-585-80000, +46-736-994409

E-mail for other authors:

Tobias Lagerbäck: tobias.lagerback@stud.ki.se

Peter Elkan: peter.elkan@sodersjukhuset.sll.se

Hans Möller: hans.moller@karolinska.se

Anna Grauers: anna.grauers@karolinska.se

Elias Diarbakerli: elias.diarbakerli@karolinska.se 
All authors had full access to all of the data and can take responsibility for the integrity of the data and the accuracy of the data analyses.

TL and PG affirm that the manuscript is an honest, accurate, and transparent account of the study being reported; no important aspects of the study have been omitted; no discrepancies from the study plan have been made.

Data sharing: no additional data available.

Key words: Adolescents, discectomy, lumbar disc hernia, outcome, surgery

Running title: Lumbar disc hernia in adolescents 


\begin{abstract}
Background Context: Disc-related sciatica has a prevalence of about $2 \%$ in adults, but is rare in adolescents. If conservative treatment is unsuccessful, surgery is an option.
\end{abstract}

Purpose: The aim of this study was to compare the outcomes of surgery for lumbar disc herniation in adolescents with adults in the SweSpine Register.

Study Design/Setting: Prospective observational study. National Quality Register.

Patient Sample: This study included 151 patients, aged 18 years or younger, 4,386 patients aged 19-39 years and 6,078 patients aged 40 years or older, followed for 1-2 years after surgery.

Outcome measures: The primary outcomes were patient satisfaction and global assessment of back and leg pain. Secondary outcomes were visual analog scale (VAS) back pain, VAS leg pain, Oswestry Disability Index (ODI), and EuroQol 5-Dimensions (EQ-5D).

Methods: Financial support has been received from the Swedish Society of Spine Surgeons. Statistical analyses were performed with the Welch F-test, the Chi-square test, and the Wilcoxon test.

Results: At follow-up, $86 \%$ of the adolescents were satisfied compared to $78 \%$ in the younger adults and $76 \%$ in the older adults group $(\mathrm{p}<0.001)$. According to the global assessment, significantly decreased leg pain was experienced by $87 \%$ of the adolescents, $78 \%$ of the younger adults and $71 \%$ of the older adults $(\mathrm{p}<0.001)$. Corresponding figures for back pain were $88 \%, 73 \%$ and $70 \%$, respectively $(\mathrm{p}<0.001)$. All groups experienced significant postoperative improvement of VAS leg pain, VAS back pain, ODI and EQ-5D (all p<0.001). 
Conclusions: The adolescent age group was more satisfied with the treatment than the adult groups. There was a significant improvement in all age groups after surgery. 


\section{Introduction}

Disc-related sciatica has a prevalence of about $2 \%$ in adults, but is rare in adolescents ${ }^{1}$. Pain relief occurs within 8 weeks of conservative, non-surgical, treatment in $80 \%$ of the cases ${ }^{2}$. When non-surgical treatment fails, surgery gives relief from symptoms ${ }^{34}$. The incidence of surgery varies worldwide ${ }^{5}$. In Sweden, approximately 20 per 100,000 individuals per year undergo surgery for a herniated lumbar disc at a median age of 40 years ${ }^{67}$.

There have been only a few studies on lumbar disc herniation in children and adolescents, and all are retrospective $\mathrm{e}^{8-16}$. The indications for surgical treatment of lumbar disc herniation in adolescents are generally: no improvement of severe pain with conservative treatment, disabling pain that affects daily activities, cauda equina syndrome, or progressive neurological deficits ${ }^{17}$. This is similar to the indications for surgery in adults. The time from onset of symptoms to diagnosis and surgical intervention is longer among adolescents than among adults $^{1018}$. This time could possibly be shortened if clinicians felt more confident in identifying and surgically intervening in cases of symptomatic lumbar disc herniation in adolescents.

We hypothesized that adolescents have a similar outcome of surgery as adults. In this study, based on prospectively collected data from the Swedish Spine Register (SweSpine), we compare the short term outcomes after surgery for lumbar disc herniation in adolescents with adults. 


\section{Methods}

\section{Participants}

The SweSpine Register has included individuals treated with surgery for lumbar disc hernias since $1993^{6}$, with the aim of studying outcomes after spine surgery. In Sweden, lumbar disc hernia surgery is performed by orthopaedic spine surgeons, who treat patients of all ages, and there are, therefore, no paediatric spine surgeons. During the last decade, the number of departments participating in the registry has varied between 35 and 39 out of the 42 to 45 departments providing spinal surgery services in Sweden. All departments and patients participate voluntarily. At the time of admission, the surgeon records data consisting of information on diagnosis and type of surgery. Any reoperations on the same spinal level were registered by the surgeon performing the reoperation, and data were available for a follow-up time up of two years for all cases.

Patients operated on for lumbar disc herniation through March 2011 were included in this study. Exclusion criteria included other diagnoses than lumbar disc hernia, missing age or date of surgery, previous spine surgery, surgery other than discectomy only, or missing outcome data. If two-year data was not available one-year data was used. From a perspective of results, one- and two-year data are similar ${ }^{6}$. Two-year data was used in 8,290 patients and one-year data was used in 2,325 patients, corresponding to a mean follow-up of 1.8 years. The 10,615 total patients were divided into three age groups: adolescents (18 years or younger), younger adults (19-39 years) and older adults (40 years and older) (Figure 1). The proportion of patients with one-year data was $26 \%$ in the adolescent group, $25 \%$ in the younger adult group and $20 \%$ in the older adult group. 


\section{Outcomes}

The primary outcomes were patient satisfaction and global assessment of back and leg pain. Secondary outcomes were visual analog scale (VAS) leg pain, VAS back pain, Oswestry Disability Index (ODI) and EuroQol 5-Dimensions (EQ-5D).

The preoperative patient self-assessment questionnaire in the SweSpine Register includes VAS for leg and back pain ${ }^{19}$, scoring from 0 (no pain) to 100 (worst possible pain). The backspecific ODI ${ }^{20}$, scoring from 0 (best possible back function) to 100 (worst possible back function), and the general health questionnaire EQ-5D ${ }^{21} 22$, scoring from -0.59 (worst possible health) to 1.0 (best possible health). The ODI and EQ-5D were added to the questionnaire from the year 2000 forward.

Identical questionnaires are mailed to the patient at the 1- and 2-year follow-ups, and also includes questions on satisfaction and global assessment of leg and back pain ${ }^{23}$. The satisfaction question is formulated as 'Are you satisfied with the surgical result?' The three possible answers were dichotomized into 'Satisfied' vs 'Uncertain' and 'Dissatisfied'. The global assessment of leg pain was formulated 'How is your leg pain today when compared to before surgery?' The five answer alternatives were dichotomized into 'Pain free' and 'Much better' vs 'Somewhat better', 'Unchanged', or 'Worse'. The global assessment question for back pain was treated in a similar way. 


\section{Statistics}

To evaluate dichotomous variables in contingency tables, the Pearson $\mathrm{Chi}^{2}$-test was used. In the case of group comparisons of dependent continuous variables, the Welch F-test analysis of variance was used since group sizes and many variances were unequal. Analysis of covariance (ANCOVA) was used for group comparisons when the possible covariates sex, smoking, type of disc herniation (central/paramedian) and duration of preoperative pain (leg or back pain; less than 3 months vs 3 months or more) were included in the analysis. The Wilcoxon signed ranks test was used to analyze continuous dependent variables within groups. In case of missing data, cases were excluded analysis by analysis. VAS leg pain, VAS back pain, ODI and EQ-5D were non-normally distributed. Descriptive data for these and other continuous variables are presented as median $\left(25^{\text {th }}, 75^{\text {th }}\right.$ percentile, and range $)$. Dichotomous data are presented as number (\%). All statistical analyses were performed with SPSS, version 22. A p-value of $<0.05$ was considered significant.

\section{Analysis of non-responders}

In a drop-out analysis we compared age, sex, type of disc herniation, and preoperative duration of back and leg pain, and the proportion of smokers in the study sample (responders) with the patients without outcome data (non-responders). The differences were small and in most studied variables without statistical significance. However, the non-responders in the adolescent group had a longer duration of back pain $(\mathrm{p}=0.038)$ compared to the responders. The non-responders in the younger adult group were in median 0.7 years younger $(\mathrm{p}<0.001)$, had a lower proportion of women $(\mathrm{p}<0.001)$, a higher proportion of central disc herniations $(\mathrm{p}=0.001)$, and a higher proportion of smokers $(\mathrm{p}<0.001)$ compared to the responders. The 
non-responders in the older adult group were in median 2.3 years younger $(\mathrm{p}<0.001)$, and had a higher proportion of smokers $(\mathrm{p}<0.001)$ compared to the responders.

\section{Study approval}

All patients gave consent to participate in the SweSpine Register. Approval of this study has been obtained from the Ethical Review Board in Stockholm (number 2012/206-31/1) and from the board of the Swedish Society of Spine Surgeons, the organization responsible for the SweSpine Register (www.4s.nu).

\section{Results}

The youngest patient was 12 years and the oldest was 90 years at the time of surgery. Age, sex, proportion of smokers, operated levels and preoperative duration of back and leg pain in the different groups are shown in Table 1. Adolescents had a significantly longer period of back and leg pain before surgery than in the adult groups. There was a higher proportion of females and lower proportion of smokers among the adolescents than in the adult groups. Preoperatively, VAS for leg pain and back pain did not differ significantly between the groups ( $p=0.37$ and $p=0.18$, respectively; Figure 2). Preoperatively, ODI was lower and EQ-5D was higher in the adolescent group ( $\mathrm{p}<0.001$ for both comparisons; Figure 2).

Postoperative satisfaction and global assessment were higher among adolescents than in the other two groups ( $\mathrm{p}<0.001$ for all comparisons; Table 2). Adjustment for sex, smoking, type of disc herniation and duration of preoperative pain did not change the outcomes substantially

(Table 2). VAS leg pain, VAS back pain, ODI, and EQ-5D improved significantly after 
surgery in all groups ( $\mathrm{p}<0.001$ for all comparisons; Figure 2). Adolescents had lower VAS, both for leg and back pain, lower ODI and higher EQ-5D at follow-up after surgery than the adult groups ( $\mathrm{p}<0.001$ for all comparisons; Figure 2). Adjustment for sex, smoking, type of disc herniation and duration of preoperative pain did not change the outcomes substantially (data not shown).

When analyzing each of the ten ODI questions and the five EQ-5D dimensions separately, the adolescents had significantly better scores when compared to the adult groups both preoperatively and at the follow-up, with the exception of the dimension "usual activities" in EQ-5D postoperatively, which did not differ significantly between the age groups (data not shown).

The number of reoperated patients within two years from surgery was 3 out of $151(2 \%)$ among adolescents, 198 out of 4,386 (5\%) among the younger adult group and 237 out of $6,078(4 \%)$ in the older adult group $(\mathrm{p}=0.12)$.

In addition, all analyses for primary and secondary outcomes were also performed after exclusion of the patients with only one-year data, and we found that the outcome results did not differ substantially (data not shown). 


\section{Discussion}

This study provides the first prospective results of surgery for lumbar disc herniation in adolescents. Lumbar disc herniation in adolescents is rare, and the proportion in this material was only $1.4 \%$. The outcome comparisons showed that adolescents operated on for lumbar disc herniation were more satisfied after surgery than adults operated on for the same condition. All age groups had significant changes for the better after surgery.

Satisfaction and global assessment scales aggregate all important dimensions experienced by the patient and give a reliable assessment of outcome ${ }^{23}$. There was a significant better outcome with surgery for adolescents, compared to the adult groups. These results are supported by a review by Lavelle et al. ${ }^{18}$, who reported that more than $90 \%$ of adolescents experienced good or excellent outcome after one year, and that they seemed to have better results than adults.

VAS scores changed significantly in all groups and the changes were well above suggested thresholds for minimal clinical important differences (MCID) for both leg and back pain ${ }^{24}$. They were also above the thresholds of $23 \mathrm{~mm}$ for back pain and $58 \mathrm{~mm}$ for leg pain corresponding to a patient self-reported outcome of 'much better' ${ }^{25}$. The changes in ODI in all groups exceeded the suggested thresholds of $13-20 \%$ for substantial clinical benefit of the treatment ${ }^{26-28}$. 
At a mean 1.8 years after surgery, the mean EQ-5D scores in the present study were 0.82 for adolescents, 0.73 for younger adults, and 0.70 for older adults. In an unpublished populationbased sample of children and adolescents $(n=48)$ aged 10-18 years, collected at our institution, the EQ-5D index was 0.95. Corresponding population-based mean values for younger adults is 0.88 , and for older adults $0.83^{29}$. Solberg et al. suggested that even though the EQ-5D had very low sensitivity and specificity values in their tests, the MCID for EQ-5D is $0.3^{26}$. The change in EQ-5D for all groups exceeded this threshold. Hence, even if surgical treatment for lumbar disc hernia improves the general quality of life, patients do not recover to 'normal' levels.

The risk of reoperation in adolescents was the same as in adults in our study and was similar to, or even lower than, the $5 \%$ rate reported during a 1-year follow-up of children treated at a specialized children's hospital ${ }^{10}$.

There was a predominance of women in the youngest age group. It can be speculated that this is due to an earlier reached maturity in women compared to men. Similar findings have been reported $^{18}$, but not all reports concur ${ }^{912}$.

This study has at least three major limitations; the lack of a non-surgically treated group, the short term follow-up, and the lack of validated questionnaires for adolescents. 
SweSpine does not contain information on outcome for non-surgically treated patients. Dang et al. ${ }^{17}$ found that most authors agreed that the result of conservative, non-surgical, treatment in adolescents is not as effective as it is in adults, and that no improvement of severe pain after 4-6 weeks of conservative treatment among adolescents should be an indication for surgery. Despite this, Cahill et al. ${ }^{10}$ reported that the mean time from onset of pain to surgical treatment was 12 months in adolescents and that the time was prolonged due to attempts with conservative treatment. Previous studies on adults have suggested that a longer duration of pain may be associated with poor outcome, however not all studies concur ${ }^{30-32}$.

The mean follow-up time in this first prospective study of lumbar disc hernia surgery at youth was 1.8 years. Retrospective reports suggest that the results deteriorate with time 13141733 . There is therefore a need for longer prospective studies. This will be possible to do in the SweSpine Register.

The outcomes used in this study have not been validated for adolescents. The SweSpine Register covers various diagnoses and patient ages. All clinics participate on a voluntary basis. For simplicity, the use of questionnaires has to be fairly uniform. An increase in the number of questionnaires, or distributing different versions to adolescents and adults, might introduce problems for the clinics and subsequently decrease the response rates. The primary outcomes were chosen since we believe that they were easily interpreted by adolescents and therefore the most reliable. All outcome variables improved in a similar way in all groups, which may indicate internal validity also in the group of adolescents. The ODI was constructed for adult patients with degenerative spinal disorders ${ }^{20}$, and some questions may 
not be applicable for all patients and ages. However, if a question is not answered a result can still be calculated.

We cannot determine whether the reason for better results for adolescents could be due to a better patient selection in this group, or unmeasured confounders. Adjustment for possible confounders did not change the results substantially.

In addition, orthopaedic spine surgeons in Sweden operate on all age groups, making it unlikely that surgeon experience and education differed between adolescents and adults patients.

The use of a nationwide registry with very high coverage gives external validity to the findings. The response rate for any one- or two-year follow-up data was $81 \%$. Solberg et al. ${ }^{34}$ studied whether a loss to follow-up would bias the outcome evaluation of patients operated on for degenerative disorders of the lumbar spine. They found that a follow-up rate of $78 \%$ would not bias conclusions of overall treatment effects. They also found that there were no indications of worse outcomes in non-respondents. Some baseline differences between the non-responders and the responders were found in this study. The directions of these differences and therefore, their possible effect on outcome were not consistent. For example, the non-responders in the adult groups were younger, but also smoked to a larger extent. We therefore believe that the conclusions of the overall treatment effects in the present study are representative. 
The age cut-off for the group of adolescents can be discussed. At the age of 18, skeletal maturity has been reached by both males and females. The same age cut-off, or even higher, has been used by others ${ }^{9}{ }^{10}$. The next cut-off, 40 years, coincides with the median age of surgery for lumbar disc hernia. Younger adults have less disc degeneration in general than older adults $^{35} 36$ and might be a better comparison to the group of adolescents. The differences in the primary outcome variables were, in general, also smaller between adolescents and the younger adults than between adolescents and the older adults.

In summary, surgery for lumbar disc herniation among adolescents gives a high rate of satisfaction, which was even higher than in adults. There was a clinically relevant improvement in all age groups, but patients still did not reach the level of the general quality of life in the normal population. Future studies should include comparison between conservative treatment and surgery for adolescents, as well as longer-term follow-ups. However, surgery for lumbar disc herniation in adolescents, with the same indications as for adults, could be considered as an effective option to conservative treatment. 


\section{References}

1. Younes M, Bejia I, Aguir Z, et al. Prevalence and risk factors of disk-related sciatica in an urban population in Tunisia. Joint, bone, spine : revue du rhumatisme 2006;73(5):53842.

2. Legrand E, Bouvard B, Audran M, et al. Sciatica from disk herniation: Medical treatment or surgery? Joint Bone Spine 2007;74(6):530-5.

3. Weber H. Lumbar disc herniation. A controlled, prospective study with ten years of observation. Spine (Phila Pa 1976) 1983;8(2):131-40.

4. Peul WC, van den Hout WB, Brand R, et al. Prolonged conservative care versus early surgery in patients with sciatica caused by lumbar disc herniation: two year results of a randomised controlled trial. BMJ 2008;336(7657):1355-8.

5. Cherkin DC, Deyo RA, Loeser JD, et al. An international comparison of back surgery rates. Spine (Phila Pa 1976) 1994;19(11):1201-6.

6. Stromqvist B, Fritzell P, Hagg O, et al. Swespine: the Swedish spine register : the 2012 report. Eur Spine J 2013;22(4):953-74.

7. Spangfort EV. The lumbar disc herniation. A computer-aided analysis of 2,504 operations. Acta orthopaedica Scandinavica Supplementum 1972;142:1-95.

8. Kumar R, Kumar V, Das NK, et al. Adolescent lumbar disc disease: findings and outcome. Childs Nerv Syst 2007;23(11):1295-9.

9. Wang H, Cheng J, Xiao H, et al. Adolescent lumbar disc herniation: experience from a large minimally invasive treatment centre for lumbar degenerative disease in Chongqing, China. Clin Neurol Neurosurg 2013;115(8):1415-9.

10. Cahill KS, Dunn I, Gunnarsson T, et al. Lumbar microdiscectomy in pediatric patients: a large single-institution series. J Neurosurg Spine 2010;12(2):165-70.

11. DeLuca PF, Mason DE, Weiand R, et al. Excision of herniated nucleus pulposus in children and adolescents. J Pediatr Orthop 1994;14(3):318-22.

12. Papagelopoulos PJ, Shaughnessy WJ, Ebersold MJ, et al. Long-term outcome of lumbar discectomy in children and adolescents sixteen years of age or younger. J Bone Joint Surg Am 1998;80(5):689-98.

13. Parisini P, Di Silvestre M, Greggi T, et al. Lumbar disc excision in children and adolescents. Spine (Phila Pa 1976) 2001;26(18):1997-2000.

14. Ozgen S, Konya D, Toktas OZ, et al. Lumbar disc herniation in adolescence. Pediatric neurosurgery 2007;43(2):77-81.

15. Kurth AA, Rau S, Wang C, et al. Treatment of lumbar disc herniation in the second decade of life. Eur Spine J 1996;5(4):220-4.

16. DeOrio JK, Bianco AJ, Jr. Lumbar disc excision in children and adolescents. J Bone Joint Surg Am 1982;64(7):991-6.

17. Dang L, Liu Z. A review of current treatment for lumbar disc herniation in children and adolescents. Eur Spine J 2010;19(2):205-14.

18. Lavelle WF, Bianco A, Mason R, et al. Pediatric disk herniation. J Am Acad Orthop Surg 2011;19(11):649-56.

19. Briggs M. A descriptive study of the use of visual analogue scales and verbal rating scales for the assessment of postoperative pain in orthopedic patients. Journal of Pain and Symptom Management 1999;18(6):438-46.

20. Fairbank JC, Pynsent PB. The Oswestry Disability Index. Spine (Phila Pa 1976) 2000;25(22):2940-52; discussion 52.

21. Brooks R. EuroQol: the current state of play. Health Policy 1996;37(1):53-72. 
22. Burstrom K, Johannesson M, Diderichsen F. Health-related quality of life by disease and socio-economic group in the general population in Sweden. Health Policy 2001;55(1):51-69.

23. Hagg O, Fritzell P, Oden A, et al. Simplifying outcome measurement: evaluation of instruments for measuring outcome after fusion surgery for chronic low back pain. Spine (Phila Pa 1976) 2002;27(11):1213-22.

24. Singer AJ, Thode HC, Jr. Determination of the minimal clinically significant difference on a patient visual analog satisfaction scale. Acad Emerg Med 1998;5(10):1007-11.

25. Zanoli G. Outcome assessment in lumbar spine surgery. Acta Orthop Suppl 2005;76(318):5-47.

26. Solberg T, Johnsen LG, Nygaard OP, et al. Can we define success criteria for lumbar disc surgery? : estimates for a substantial amount of improvement in core outcome measures. Acta Orthop 2013;84(2):196-201.

27. Copay AG, Glassman SD, Subach BR, et al. Minimum clinically important difference in lumbar spine surgery patients: a choice of methods using the Oswestry Disability Index, Medical Outcomes Study questionnaire Short Form 36, and pain scales. Spine J 2008;8(6):968-74.

28. Glassman SD, Copay AG, Berven SH, et al. Defining substantial clinical benefit following lumbar spine arthrodesis. J Bone Joint Surg Am 2008;90(9):1839-47.

29. Burstrom K, Johannesson M, Diderichsen F. Swedish population health-related quality of life results using the EQ-5D. Qual Life Res 2001;10(7):621-35.

30. Stromqvist B, Fritzell P, Hagg O, et al. The National Swedish Register for Lumbar Spine Surgery. Report 2008. Acquired at http://www4snu/pdf/Ryggregisterrapport_2008_eng_versionpdf.

31. Peul WC, van Houwelingen HC, van den Hout WB, et al. Surgery versus prolonged conservative treatment for sciatica. N Engl J Med 2007;356(22):2245-56.

32. Lequin MB, Verbaan D, Jacobs WC, et al. Surgery versus prolonged conservative treatment for sciatica: 5-year results of a randomised controlled trial. BMJ Open 2013;3(5).

33. Silvers HR, Lewis PJ, Clabeaux DE, et al. Lumbar disc excisions in patients under the age of 21 years. Spine (Phila Pa 1976) 1994;19(21):2387-91; discussion 92.

34. Solberg TK, Sorlie A, Sjaavik K, et al. Would loss to follow-up bias the outcome evaluation of patients operated for degenerative disorders of the lumbar spine? Acta Orthop 2011;82(1):56-63.

35. Buckwalter JA. Aging and degeneration of the human intervertebral disc. Spine (Phila Pa 1976) 1995;20(11):1307-14.

36. Boos N, Weissbach S, Rohrbach H, et al. Classification of age-related changes in lumbar intervertebral discs: 2002 Volvo Award in basic science. Spine (Phila Pa 1976) 2002;27(23):2631-44. 


\section{Tables}

Table 1. Characteristics of the three age groups at time of surgery. Data given as median $\left(25^{\text {th }}\right.$, $75^{\text {th }}$ percentile) or as number (\%). P-values are given for the Pearson $\mathrm{Chi}^{2}$-test for the differences between the three groups. Numbers in the table do not always correspond to group numbers due to missing data.

\begin{tabular}{|c|c|c|c|c|}
\hline & $\begin{array}{l}\text { Age } \leq 18 \text { years } \\
(\mathrm{n}=151)\end{array}$ & $\begin{array}{l}\text { Age } 19-39 \text { years } \\
(n=4,386)\end{array}$ & $\begin{array}{l}\text { Age } \geq 40 \text { years } \\
(\mathrm{n}=6,078)\end{array}$ & P-value \\
\hline Age (years) & $17.8(16.7,18.5)$ & $33.9(29.7,37.1)$ & $50.1(44.5,58.2)$ & - \\
\hline Number of women & $76(50 \%)$ & $1,918(44 \%)$ & $2,796(46 \%)$ & $\mathrm{p}=0.030$ \\
\hline \multicolumn{5}{|l|}{ Operated level } \\
\hline L4-L5 & $70(46 \%)$ & $1,471(34 \%)$ & $2,617(43 \%)$ & \\
\hline L5-S1 & $72(48 \%)$ & $2,601(59 \%)$ & $2,583(43 \%)$ & \\
\hline $\begin{array}{l}\text { Other level, unknown level or } \\
\text { multiple levels }\end{array}$ & $9(6 \%)$ & $314(7 \%)$ & $878(14 \%)$ & $\mathrm{p}<0.001$ \\
\hline \multicolumn{5}{|l|}{ Type of disc herniation } \\
\hline Paramedian & $141(93 \%)$ & $4,014(92 \%)$ & $5,510(91 \%)$ & \\
\hline Central & $10(7 \%)$ & $372(8 \%)$ & $568(9 \%)$ & $\mathrm{p}=0.19$ \\
\hline \multicolumn{5}{|l|}{ Duration of back pain } \\
\hline$<3$ months of pain & $15(13 \%)$ & $467(14 \%)$ & $773(17 \%)$ & \\
\hline$\geq 3$ months of pain & $103(87 \%)$ & $2,961(86 \%)$ & $3,856(83 \%)$ & $\mathrm{P}=0.001$ \\
\hline \multicolumn{5}{|l|}{ Duration of leg pain } \\
\hline$<3$ months of pain & $15(12 \%)$ & $620(17 \%)$ & $985(20 \%)$ & \\
\hline$\geq 3$ months of pain & $112(88 \%)$ & $2,959(83 \%)$ & $3,938(80 \%)$ & $\mathrm{p}=0.001$ \\
\hline \multicolumn{5}{|l|}{ Smoking status } \\
\hline Smoker & $10(8 \%)$ & $689(19 \%)$ & $1,139(23 \%)$ & \\
\hline Non-smoker & $116(92 \%)$ & $2,858(81 \%)$ & $3,775(77 \%)$ & $\mathrm{p}<0.001$ \\
\hline
\end{tabular}


Table 2. Satisfaction and global assessment one to two years after surgery. Data are given as number (\%). Unadjusted P-values are given for the Pearson $\mathrm{Chi}^{2}$-test, and adjusted p-values for analysis of covariance after adjustment for sex, smoking, type of disc herniation and duration of preoperative leg and back pain for the differences between the three groups. Numbers in the table do not always correspond to group numbers due to missing data.

\begin{tabular}{|c|c|c|c|c|c|}
\hline & $\begin{array}{l}\text { Age } \leq 18 \text { years } \\
(\mathrm{n}=151)\end{array}$ & $\begin{array}{l}\text { Age } 19-39 \text { years } \\
(n=4,386)\end{array}$ & $\begin{array}{l}\text { Age } \geq 40 \text { years } \\
(n=6,078)\end{array}$ & $\begin{array}{l}\text { Unadjusted } \\
\text { p-value }\end{array}$ & $\begin{array}{l}\text { Adjusted p- } \\
\text { value }\end{array}$ \\
\hline \multicolumn{6}{|l|}{ Satisfaction } \\
\hline Satisfied & $128(86 \%)$ & $3,362(78 \%)$ & $4,479(76 \%)$ & & \\
\hline Uncertain/dissatisfied & $21(14 \%)$ & $925(22 \%)$ & $1,436(24 \%)$ & $\mathrm{p}<0.001$ & $\mathrm{p}=0.043$ \\
\hline \multicolumn{6}{|l|}{$\underline{\text { Global assessment leg pain }}^{a}$} \\
\hline Pain free/Much better & $130(87 \%)$ & $3,337(78 \%)$ & $4,191(71 \%)$ & & \\
\hline Somewhat better/unchanged/worse & $20(13 \%)$ & $951(22 \%)$ & $1,691(29 \%)$ & $\mathrm{p}<0.001$ & $\mathrm{p}<0.001$ \\
\hline \multicolumn{6}{|l|}{$\underline{\text { Global assessment back pain }}^{b}$} \\
\hline Pain free/Much better & $120(88 \%)$ & $3,025(73 \%)$ & $3,959(70 \%)$ & & \\
\hline Somewhat better/unchanged/worse & $17(12 \%)$ & $1,108(27 \%)$ & $1,714(30 \%)$ & $\mathrm{p}<0.001$ & $\mathrm{p}<0.001$ \\
\hline
\end{tabular}

${ }^{a}$ There were 0 adolescents, 43 younger adults and 94 older adults that did not experience leg pain before surgery.

${ }^{b}$ There were 12 adolescents, 189 younger adults and 312 older adults that did not have back pain before surgery. 


\section{Figures}

Figure 1. Flow chart of the patients in the study. A total of 10,615 patients were divided into three groups: adolescents (18 years or younger), younger adults (19-39 years) and older adults (age 40 years and older).

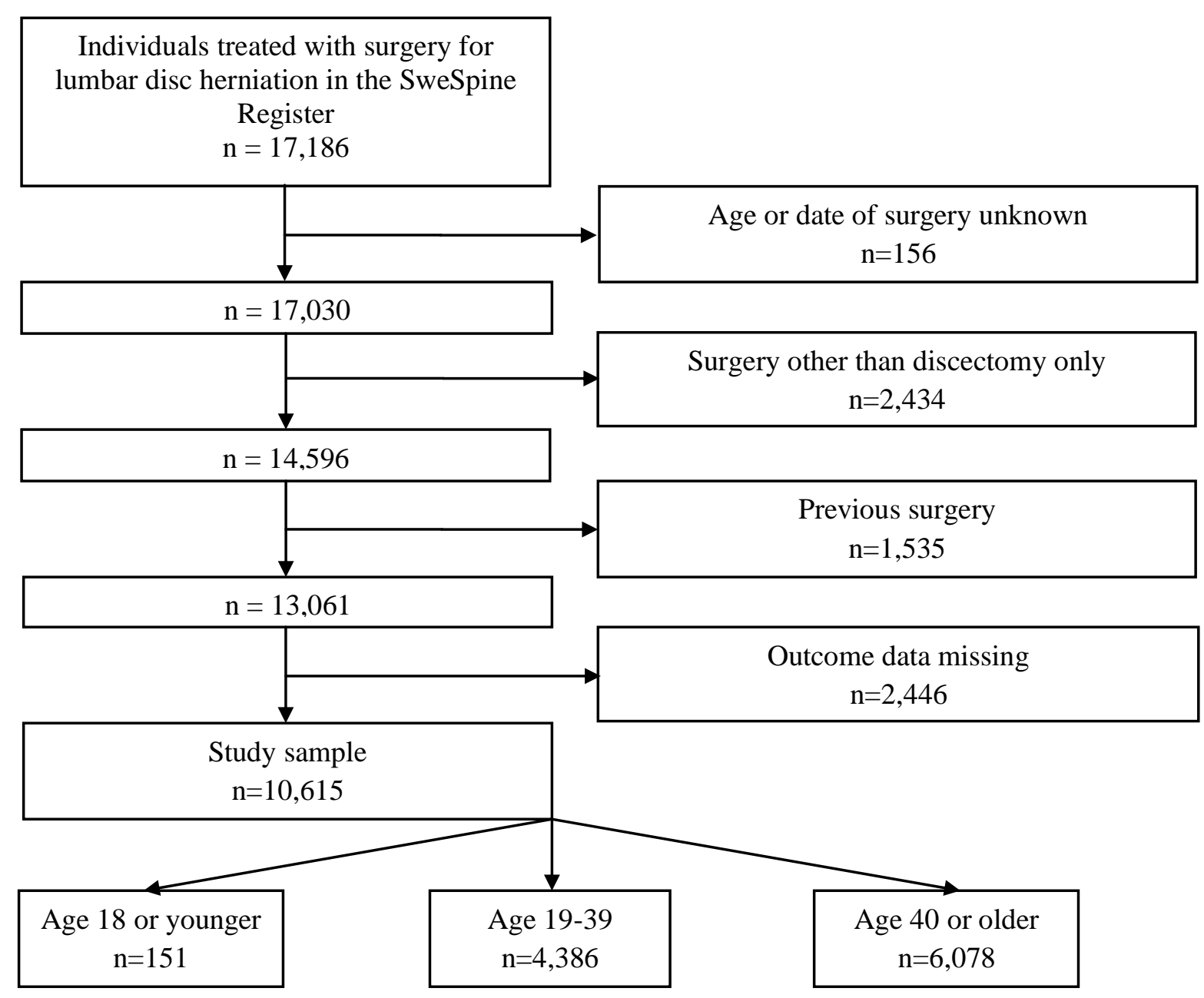


Figure 2. Comparison of secondary outcomes preoperatively and at follow-up. The Welch Ftest was used for group comparisons and the Wilcoxon signed ranks test was used for changes within groups. Preoperatively, adolescents had similar VAS leg pain $(p=0.37)$ and VAS back pain $(\mathrm{p}=0.18)$, while ODI was significantly lower $(\mathrm{p}<0.001)$ and EQ5D was significantly higher $(\mathrm{p}<0.001)$ when compared to the adult groups. All groups experienced significant improvement in all outcome variables ( $\mathrm{p}<0.001$ for all comparisons). At follow-up, adolescents had significantly lower VAS leg pain, VAS back pain and ODI, and higher EQ$5 \mathrm{D}$ than the adult groups ( $\mathrm{p}<0.001$ for all comparisons). The boxes show median and interquartile ranges; inner fences represent minimum and maximum values, or 1.5 times the interquartile range. Outliers are indicated. $\mathrm{N}=$ number of patients available in each group.

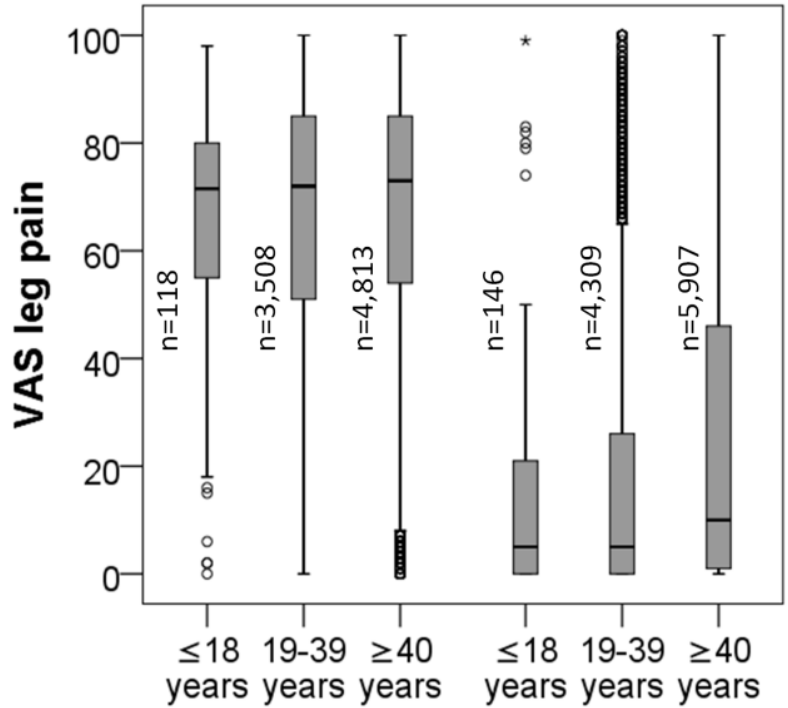

Preop

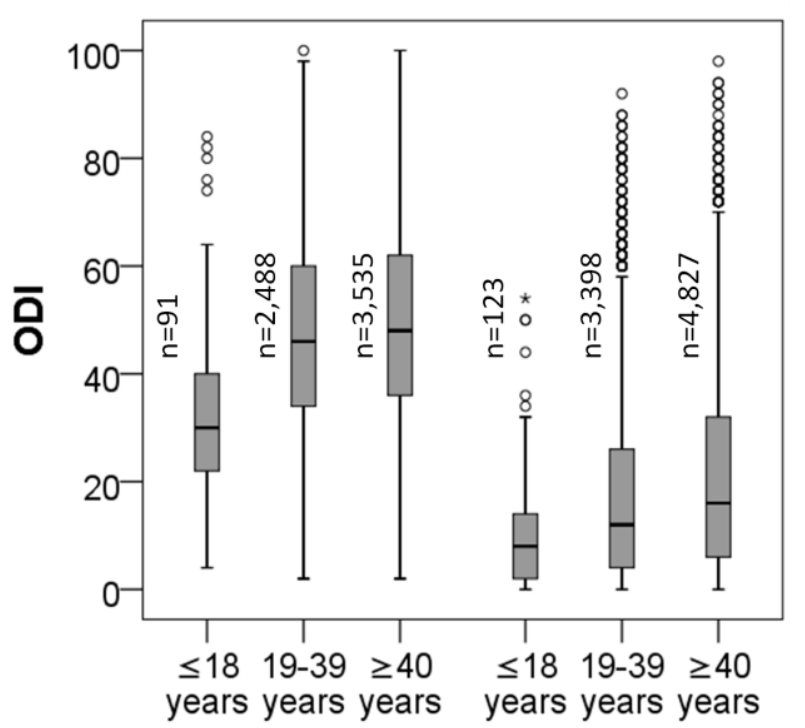

Preop

Follow-up

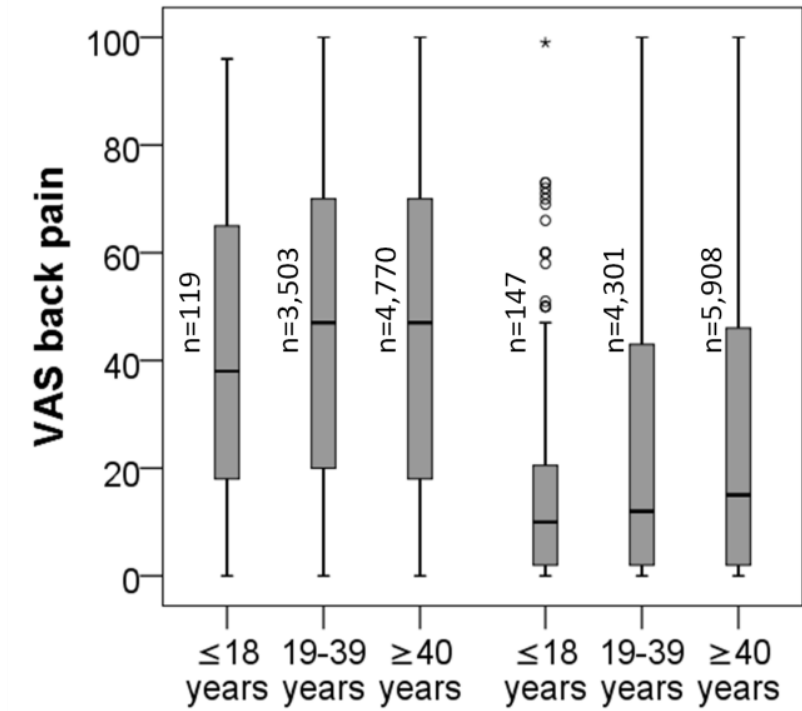

Preop

Follow-up

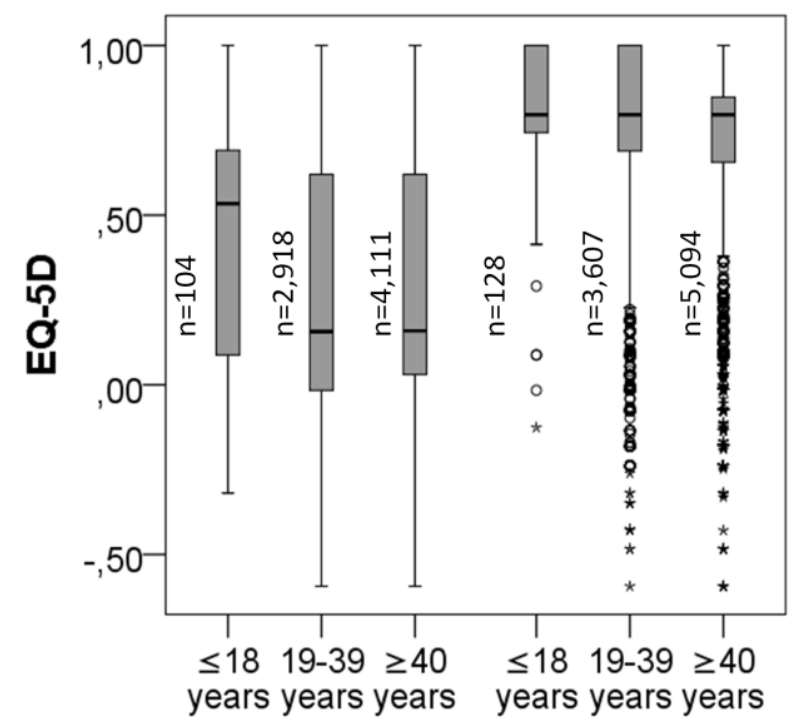

Preop

Follow-up 